\title{
Estaquia de mirtilo nas estações do ano com ácido indolbutírico e aquecimento do substrato
}

\author{
Marcos Aurélio Marangon ${ }^{(1)}$ e Luiz Antonio Biasi(2) \\ (1)Embrapa Transferência de Tecnologia, Escritório de Negócios de Canoinhas, BR280, Km219, Caixa Postal317, CEP89460-000 Canoinhas, SC. \\ E-mail: marcos.marangon@embrapa.br ${ }^{(2)}$ Universidade Federal do Paraná, Departamento de Fitotecnia e Fitossanitarismo, Setor de Ciências \\ Agrárias, Rua dos Funcionários, № 1.540, CEP 80035-050 Curitiba, PR. E-mail: biasi@ufpr.br
}

Resumo - O objetivo deste trabalho foi avaliar os efeitos da aplicação de concentrações do ácido indolbutírico (AIB) e do aquecimento do substrato sobre o enraizamento de estacas caulinares das cultivares de mirtilo Bluebelle, Bluegem e Powderblue, nas quatro estações do ano. Utilizou-se o delineamento experimental inteiramente casualizado, com arranjo fatorial $4 \times 5 \times 2$ (estações $\mathrm{x}$ concentrações de AIB $\times$ com e sem aquecimento do substrato), com 4 repetições e 20 estacas como unidade experimental. Foram avaliadas as percentagens de estacas enraizadas, mortas, vivas e com calo, e o número e o comprimento médio de raízes. As maiores percentagens de enraizamento foram $57,1 \%$ na 'Bluegem', no verão, $30 \%$ na 'Bluebelle', na primavera, com aquecimento, e $63 \%$ na 'Powderblue', no verão, com aquecimento. O AIB na concentração de $2.000 \mathrm{mg} \mathrm{L}^{-1}$ aumentou o enraizamento de estacas das cultivares Bluegem e Powderblue. O aquecimento do substrato melhora o enraizamento das estacas coletadas no outono e no inverno, em todas as cultivares e, também, das estacas coletadas no verão e na primavera, na cultivar Bluebelle.

Termos para indexação: Vaccinium ashei, auxina, enraizamento, propagação vegetativa.

\section{Cutting propagation of blueberry in seasons of the year with indolebutyric acid and bottom heat}

\begin{abstract}
The objective of this work was to evaluate the effects of the application of concentrations of indolebutyric acid (IBA) and of bottom heat on rooting of stem cuttings of the blueberry cultivars Bluebelle, Bluegem, and Powderblue in the four seasons of the year. A completely randomized design was used, with a $4 \times 5 \times 2$ factorial arrangement (seasons $x$ concentrations of IBA $x$ with and without heat), with 4 replicates and 20 stem cuttings as an experimental unit. The percentage of rooted cuttings, dead, alive and with callus, and the number and average length of the roots were evaluated. The highest rooting percentages were $57.1 \%$ for 'Bluegem' in summer, 30\% for 'Bluebelle' in spring, with heating, and $63 \%$ for 'Powderblue' in summer with heating. IBA at the concentration of $2,000 \mathrm{mg} \mathrm{L}^{-1}$ increased the rooting of cuttings of the cultivars Bluegem and 'Powderblue'. Bottom heat increases the rooting of the cuttings harvested during autumn and winter in all cultivars, and also the cuttings harvested during summer and spring in the Bluebelle cultivar.
\end{abstract}

Index terms: Vaccinium ashei, auxin, rooting, vegetative propagation.

\section{Introdução}

O mirtilo (Vaccinium spp.) é uma espécie frutífera originária de algumas regiões da Europa e da América do Norte, onde é muito apreciada em razão do seu sabor agridoce e das suas propriedades como alimento funcional (Antunes, 2006). Cultivares do grupo "highbush" (Vaccinium corymbosum L.) e do grupo "rabbiteye" ( $V$. ashei) apresentam elevados teores de antocianinas e fenóis totais, além de elevada atividade antioxidante (Beccaro et al., 2006; Rodrigues et al., 2011). Essas características nutracêuticas atraem consumidores de diversos níveis econômicos, e a fruta atinge altos valores no mercado externo, o que representa boa alternativa para a cadeia produtiva de regiões ainda com pouca tradição na produção da fruta, como a América do Sul (Madail \& Santos, 2006).

Os Estados Unidos é o maior produtor de mirtilo e produziu, em 2010, $188.150 \mathrm{Mg}$, o que representou mais de $60 \%$ da produção mundial, seguido pelo Canadá, com $83.507 \mathrm{Mg}$. Juntos, estes países representaram mais de $87 \%$ da produção total (Food and Agriculture Organization of the United Nations, 2012). Os Estados Unidos, além de maior produtor, também é um grande importador, uma vez que o elevado índice de consumo interno absorve cerca de $82 \%$ da produção do restante do mundo no período de 
entressafra. Dessa forma, cria-se uma oportunidade para os países do hemisfério sul abastecerem esse mercado, como já ocorre com o Chile e a Argentina, de outubro a abril (Madail \& Santos, 2006). O Brasil não aparece nas estatísticas oficiais, pois sua produção ainda é muito pequena. Em 2004, estimou-se que a área de produção, no país, era de apenas 25 ha (Banados, 2006). Entre as diversas cultivares estudadas no Brasil, destacam-se, como as mais produtivas, a Bluebelle, a Briteblue e a Bluegem (Antunes et al., 2008).

Essa frutífera se enquadra muito bem no nicho da agricultura familiar, pois requer uso intensivo de mão de obra, alto valor agregado por área, pequenas áreas para o cultivo, colheita de forma escalonada por vários dias e baixo índice de mecanização, o que oferece inúmeras possibilidades para a indústria caseira e as pequenas agroindústrias.

A procura pelo mirtilo no mercado interno tem sido grande, mas a expansão das áreas de cultivo não acompanha esta demanda. Entre os fatores que dificultam a expansão, está a pequena disponibilidade de mudas oferecidas pelos viveiristas, resultante da dificuldade técnica de propagação desta espécie frutífera. A propagação por sementes, em nível comercial, não é utilizada, pois a segregação genética origina descendentes com características diferentes da planta matriz (Hoffmann et al., 1995). Contudo, bons resultados têm sido obtidos na micropropagação para a produção de mudas, dependendo da cultivar (Zhang et al., 2006; Schuch et al., 2008; Damiani \& Schuch, 2009), e, também, na microestaquia a partir de plantas matrizes micropropagadas (Schuch et al., 2007; Pelizza et al., 2011). A produção comercial de mudas é basicamente obtida pela estaquia. Entretanto, os resultados dessa técnica variam de acordo com a cultivar (Fischer et al., 2008a, 2008b; Trevisan et al., 2008; Peña et al., 2012) e com as condições ambientais de cada viveiro (Piller et al., 2002).

O conhecimento sobre a capacidade de enraizamento das cultivares e sua resposta à aplicação de reguladores vegetais permite a obtenção de resultados mais satisfatórios na propagação por estaquia (Fachinello et al., 2005).

O objetivo deste trabalho foi avaliar os efeitos da aplicação de concentrações do ácido indolbutírico (AIB) e do aquecimento do substrato sobre o enraizamento de estacas caulinares das cultivares de mirtilo Bluebelle, Bluegem e Powderblue, nas quatro estações do ano.

\section{Material e Métodos}

O trabalho foi realizado na Embrapa Transferência de Tecnologia, no município de Canoinhas, SC $\left(26^{\circ} 10^{\prime} \mathrm{S}\right.$ $50^{\circ} 23^{\prime} \mathrm{W}$, a $765 \mathrm{~m}$ de altitude), em casa de vegetação com sistema automático de irrigação por nebulização intermitente. $\mathrm{O}$ material vegetal foi obtido de plantas matrizes mantidas na mesma instituição, oriundas da coleção de cultivares de mirtilo, pertencente à Embrapa Clima Temperado, em Pelotas, RS. As cultivares utilizadas foram Bluebelle, Bluegem e Powderblue.

As estacas foram coletadas nas quatro estações do ano: outono (15/4/2008), inverno (15/7/2008), primavera (15/10/2008) e verão (15/1/2009), com e sem aquecimento do substrato. As estacas foram preparadas com $15 \mathrm{~cm}$ de comprimento e com diâmetro aproximado de $6 \mathrm{~mm}$, tendo-se mantido duas folhas cortadas ao meio, no terço superior. Após o preparo, as estacas foram desinfestadas por imersão numa solução de hipoclorito de sódio a $0,5 \%$, por 10 min, com posterior lavagem em água corrente por 5 min. Em seguida, lesionou-se a base das estacas $(2 \mathrm{~cm})$ para exposição do câmbio à solução de ácido indolbutírico (AIB), por imersão rápida da base por $10 \mathrm{~s}$, nas concentrações de 0 (testemunha), 250, 500, 1.000 e $2.000 \mathrm{mg} \mathrm{L}^{-1}$. Utilizou-se o delineamento experimental inteiramente casualizado, com arranjo fatorial 4x5x2 (estações x concentrações de AIB x com e sem aquecimento do substrato), com 4 repetições, e as unidades experimentais foram formadas por 20 estacas. Os dados foram analisados, separadamente, de acordo com cada cultivar.

As estacas foram mantidas em substrato formado pela mistura volumétrica de areia e substrato comercial Plantmax HF (9:1), colocado em bandejas metálicas de $1 \times 1 \times 0,1 \mathrm{~m}$. O substrato foi aquecido por canos de cobre, em forma de serpentina, por onde circulava água aquecida por resistências. Para o controle da temperatura, utilizou-se um termostato de 0 a $50^{\circ} \mathrm{C}$, com variação de $1,5^{\circ} \mathrm{C}$, e um contactor de $10 \mathrm{~A}$ para acionar as resistências. Um termostato com sensor acionava as resistências quando a temperatura do substrato era inferior a $24^{\circ} \mathrm{C}$.

A avaliação foi realizada sempre 90 dias após a instalação de cada época de estaquia. As variáveis avaliadas foram: percentagem de estacas enraizadas (estacas que se apresentaram vivas e com indução de primórdios radiciais, com no mínimo $1 \mathrm{~mm}$ de comprimento, com ou sem calos); percentagem de 
estacas vivas (estacas que se apresentaram vivas, sem indução do primórdio radicular e sem formação de calos); percentagem de estacas com calo (estacas que se apresentaram vivas e com formação apenas de calo); percentagem de estacas mortas; número de raízes por estaca (número total de raízes primárias por estaca enraizada); e comprimento médio das raízes (média do comprimento das três maiores raízes por estaca enraizada em $\mathrm{cm}$ ).

Os dados obtidos foram submetidos à análise de variância, e as médias foram comparadas pelo teste de Tukey, a 5\% de probabilidade. O programa estatístico utilizado foi o Sisvar.

\section{Resultados e Discussão}

Nas três cultivares avaliadas, não houve interação tripla significativa para as variáveis analisadas. No entanto, houve interação dupla entre épocas de coleta e aquecimento do substrato, com exceção da percentagem de estacas enraizadas e de estacas com calo da cultivar Bluegem. Nesta cultivar, estacas coletadas no verão apresentaram maior percentagem de enraizamento $(57,1 \%)$, e as estacas coletadas na primavera resultaram em maior formação de calo (13\%) (Tabela 1). Na cultivar Powderblue, a percentagem de enraizamento também foi superior no verão, nas estacas em substrato aquecido ou não. Em relação à 'Bluebelle', as estacas coletadas na primavera apresentaram maior enraizamento (30\%) com o aquecimento do substrato, tendo-se observado diferença entre as coletadas no inverno e no verão; porém, sem o aquecimento, não houve diferença entre as épocas de coleta. Diferentemente do verificado no presente trabalho, Fischer et al. (2008b), em Pelotas, RS, obtiveram $67,5 \%$ de enraizamento com estaquia lenhosa sem utilização de auxina e sem aquecimento do substrato.

Tabela 1. Percentagem de estacas enraizadas, mortas, vivas e com calo das cultivares de mirtilo Bluegem, Bluebelle e Powderblue, tratadas com diferentes concentrações de ácido indolbutírico em substrato com e sem aquecimento, nas quatro estações do ano ${ }^{(1)}$.

\begin{tabular}{|c|c|c|c|c|c|c|c|}
\hline \multirow[t]{2}{*}{ Estação } & \multicolumn{3}{|c|}{ Bluegem } & \multicolumn{2}{|c|}{ Bluebelle } & \multicolumn{2}{|c|}{ Powderblue } \\
\hline & Com aquecimento & Média & Sem aquecimento & Com aquecimento & $\overline{\text { Sem aquecimento }}$ & Com aquecimento & Sem aquecimento \\
\hline & \multicolumn{7}{|c|}{ Estacas enraizadas $(\%)$} \\
\hline Outono & - & $27,4 \mathrm{c}$ & - & $23,5 \mathrm{Aab}$ & $14,0 \mathrm{Ba}$ & $49,7 \mathrm{Ab}$ & $25,7 \mathrm{Bc}$ \\
\hline Inverno & - & $16,1 d$ & - & $20,2 \mathrm{Ac}$ & $13,2 \mathrm{Ba}$ & $24,7 \mathrm{Ac}$ & $13,2 \mathrm{Bd}$ \\
\hline Primavera & - & $47,5 b$ & - & $30,0 \mathrm{Aa}$ & $16,7 \mathrm{Ba}$ & $49,2 \mathrm{Ab}$ & $46,7 \mathrm{Ab}$ \\
\hline Verão & - & $57,1 \mathrm{a}$ & - & $22,5 \mathrm{Ab}$ & $16,2 \mathrm{Ba}$ & $63,0 \mathrm{Aa}$ & $59,2 \mathrm{Aa}$ \\
\hline \multirow[t]{2}{*}{$\mathrm{CV}(\%)$} & & 26,66 & & \multicolumn{2}{|c|}{42,90} & \multicolumn{2}{|c|}{28,58} \\
\hline & \multicolumn{7}{|c|}{ Estacas mortas (\%) } \\
\hline Outono & $31,5 \mathrm{Ab}$ & - & $26,5 \mathrm{Bb}$ & $20,5 \mathrm{Ac}$ & $13,5 \mathrm{Bc}$ & $4,7 \mathrm{Bc}$ & $13,7 \mathrm{Ab}$ \\
\hline Inverno & $55,0 \mathrm{Ba}$ & - & $67,5 \mathrm{Aa}$ & $59,8 \mathrm{Aa}$ & $55,0 \mathrm{Aa}$ & $43,0 \mathrm{Ba}$ & $59,5 \mathrm{Aa}$ \\
\hline Primavera & $21,7 \mathrm{Ac}$ & - & $23,5 \mathrm{Ab}$ & $35,5 \mathrm{Bb}$ & $42,2 \mathrm{Ab}$ & $11,0 \mathrm{Ab}$ & $12,5 \mathrm{Ab}$ \\
\hline Verão & $6,5 \mathrm{Ad}$ & - & $9,8 \mathrm{Ac}$ & $38,5 \mathrm{Ab}$ & $41,0 \mathrm{Ab}$ & $4,2 \mathrm{Ac}$ & $5,7 \mathrm{Ac}$ \\
\hline \multirow[t]{2}{*}{ CV (\%) } & & 25,96 & & \multicolumn{2}{|c|}{20,89} & \multicolumn{2}{|c|}{36,84} \\
\hline & \multicolumn{7}{|c|}{ Estacas vivas (\%) } \\
\hline Outono & $30,5 \mathrm{Ba}$ & - & $42,5 \mathrm{Aa}$ & $49,0 \mathrm{Ba}$ & $66,5 \mathrm{Aa}$ & $30,7 \mathrm{Ba}$ & $46,0 \mathrm{Aa}$ \\
\hline Inverno & $14,0 \mathrm{Bb}$ & - & $21,0 \mathrm{Ac}$ & $24,0 \mathrm{Ab}$ & $21,0 \mathrm{Ac}$ & $18,5 \mathrm{Bb}$ & $24,0 \mathrm{Ab}$ \\
\hline Primavera & $17,8 \mathrm{Ab}$ & - & $16,0 \mathrm{Ad}$ & $27,5 \mathrm{Ab}$ & $25,0 \mathrm{Ab}$ & $33,2 \mathrm{Aa}$ & $35,0 \mathrm{Aa}$ \\
\hline Verão & $29,0 \mathrm{Aa}$ & - & $30,7 \mathrm{Ab}$ & $29,5 \mathrm{Ab}$ & $34,5 \mathrm{Ab}$ & $29,0 \mathrm{Aa}$ & $29,2 \mathrm{Aab}$ \\
\hline \multirow[t]{2}{*}{ CV (\%) } & & 29,72 & & \multicolumn{2}{|c|}{25,44} & \multicolumn{2}{|c|}{24,29} \\
\hline & \multicolumn{7}{|c|}{ Estacas com calo (\%) } \\
\hline Outono & - & $7,1 \mathrm{~b}$ & - & $7,0 \mathrm{Aa}$ & $6,0 \mathrm{Abc}$ & $14,7 \mathrm{Aa}$ & $14,5 \mathrm{Aa}$ \\
\hline Inverno & - & $5,1 b$ & - & $3,0 \mathrm{Ab}$ & $3,7 \mathrm{Ac}$ & $13,7 \mathrm{Aa}$ & $3,0 \mathrm{Bb}$ \\
\hline Primavera & - & $13,0 \mathrm{a}$ & - & $7,0 \mathrm{Ba}$ & $16,0 \mathrm{Aa}$ & $6,5 \mathrm{Ab}$ & $6,7 \mathrm{Ab}$ \\
\hline Verão & - & $4,9 \mathrm{~b}$ & - & $9,2 \mathrm{Aa}$ & $8,2 \mathrm{Ab}$ & $3,7 \mathrm{Ab}$ & $5,7 \mathrm{Ab}$ \\
\hline $\mathrm{CV}(\%)$ & - & 63,78 & - & \multicolumn{2}{|c|}{60,23} & \multicolumn{2}{|c|}{66,72} \\
\hline
\end{tabular}


Em outro estudo com as cultivares Powderblue e Climax, também foram encontrados maiores percentuais de enraizamento para estacas coletadas em novembro e março, em comparação às coletadas em agosto (Hoffmann et al., 1995). Entretanto, esse comportamento pode variar entre as espécies do gênero Vaccinium. Martinussen et al. (2006), ao avaliar o enraizamento de estacas apicais de lingonberry (Vaccinium vitis-idaea L.), observaram que as estacas enraizaram melhor no outono e no inverno.

O enraizamento de estacas semilenhosas de espécies caducifólias é maior quando as folhas estão totalmente expandidas e os ramos alcançaram certo grau de maturação. No final da primavera e no início do verão, o crescimento vegetativo das plantas é intenso e os ramos apresentam elevada atividade cambial e grande quantidade de folhas jovens, que são sítios produtores de auxinas, carboidratos e cofatores do enraizamento (Hartmann et al., 2002). Dessa forma, a presença das folhas nas estacas, nestas épocas, também deve ter sido um dos fatores responsáveis pelo maior enraizamento, conforme relatado para outras espécies, como videira (Bordin et al., 2005), maracujazeiro (Lima et al., 2007) e louro (Fochesato et al., 2006). Piller et al. (2002), ao estudar as cultivares de mirtilo Spartan e Berkeley, concluíram que a umidade e a radiação são os principais fatores que determinam a fotossíntese e a taxa de crescimento dos brotos e, consequentemente, a água e a reserva de carbono nas estacas e que a redução das reservas está associada ao baixo enraizamento. Trevisan et al. (2008) atribuíram o baixo enraizamento obtido na estaquia de mirtilo à ocorrência de um período com baixa precipitação pluvial anterior à coleta das estacas.

Os piores resultados de enraizamento, normalmente obtidos no outono e no inverno, possivelmente ocorreram porque, no outono, as plantas se preparam para a entrada em dormência, com baixa atividade nos tecidos jovens do floema secundário, dos raios vasculares e do câmbio, e com maior acúmulo de fenóis e inibidores (Hoffmann et al., 1995). No período do inverno, as plantas já se encontram em dormência, com baixa atividade fisiológica, e apresentam maior lignificação dos ramos. O maior grau de lignificação pode estar correlacionado, negativamente, à auxina, pois enzimas, como as peroxidases, participam tanto da síntese de lignina, como da degradação de auxina (Passardi et al., 2005).
Oaquecimentodosubstratoelevousignificativamente o enraizamento da cultivar Powderblue apenas no outono e no inverno (Tabela 1), e o das cultivares Bluegem e Bluebelle nas quatro estações do ano (Tabela 2). O efeito positivo do aquecimento do substrato observado na 'Bluebelle', mesmo nas estações mais quentes do ano, provavelmente ocorreu por esta ser uma cultivar com maior dificuldade de enraizamento de estacas semilenhosas (Fischer et al., 2008a), em que a falta de algum componente promotor ou a presença de inibidores do enraizamento foi compensada pelo equilíbrio da temperatura do substrato.

Todas as cultivares apresentaram maior percentagem de estacas mortas no inverno, com valores acima de $43 \%$, o que mostra que esta época é menos favorável para a estaquia do mirtilo. O aquecimento do substrato reduziu significativamente a mortalidade das estacas da cultivar Bluegem no inverno, da Bluebelle na primavera e da Powderblue no outono e no inverno, tendo acompanhado, de forma inversa, o aumento do enraizamento verificado nos mesmos tratamentos.

Muitas estacas ainda estavam vivas, mas sem raízes, no momento da avaliação, o que indica que o ambiente da estaquia apresenta condições adequadas para a manutenção prolongada das estacas e que estas ainda tinham reservas suficientes para sua sobrevivência. Contudo, não há como garantir que as estacas vivas iriam enraizar, pois já estavam 90 dias no leito de enraizamento. Portanto, com mais de $29 \%$ de estacas vivas das cultivares Bluegem e Bluebelle, no outono, e da Powderblue, no verão, na primavera e no outono, recomenda-se que, nestes casos, a estaquia seja avaliada mais tardiamente.

$\mathrm{O}$ aquecimento não aumentou a percentagem de estacas vivas em nenhuma época ou cultivar, mas as

Tabela 2. Percentagem de estacas enraizadas e com calo da cultivar de mirtilo Bluegem, tratadas com diferentes concentrações de ácido indolbutírico, nas quatro estações do ano, sob efeito do aquecimento do substrato ${ }^{(1)}$.

\begin{tabular}{lcc}
\hline Aquecimento & Estacas enraizadas (\%) & Estacas com calo (\%) \\
\hline Sem & $34,3 \mathrm{~b}$ & $8,1 \mathrm{a}$ \\
Com & $39,7 \mathrm{a}$ & $6,9 \mathrm{a}$ \\
\hline $\mathrm{CV}(\%)$ & 26,66 & 63,78 \\
\hline \multicolumn{2}{l}{ Médias seguidas de letras iguais não diferem pelo teste de Tukey, a 5\% } \\
de probabilidade.
\end{tabular}


reduziu no outono e no inverno, em decorrência do aumento da percentagem de estacas enraizadas.

A percentagem de estacas com calo não aumentou, e os maiores valores foram inferiores a $16 \%$ nas cultivares Bluebelle e Bluegem, na primavera, e na Powderblue no outono. O aquecimento do substrato teve efeito apenas no inverno, para a cultivar Powderblue.

A lesão realizada na base das estacas pode ter favorecido a formação do calo cicatricial, pela retomada da atividade mitótica. A divisão celular é estimulada pelo aumento na taxa respiratória e nos teores de auxina, carboidratos e etileno nessa área lesionada. As raízes adventícias podem ser
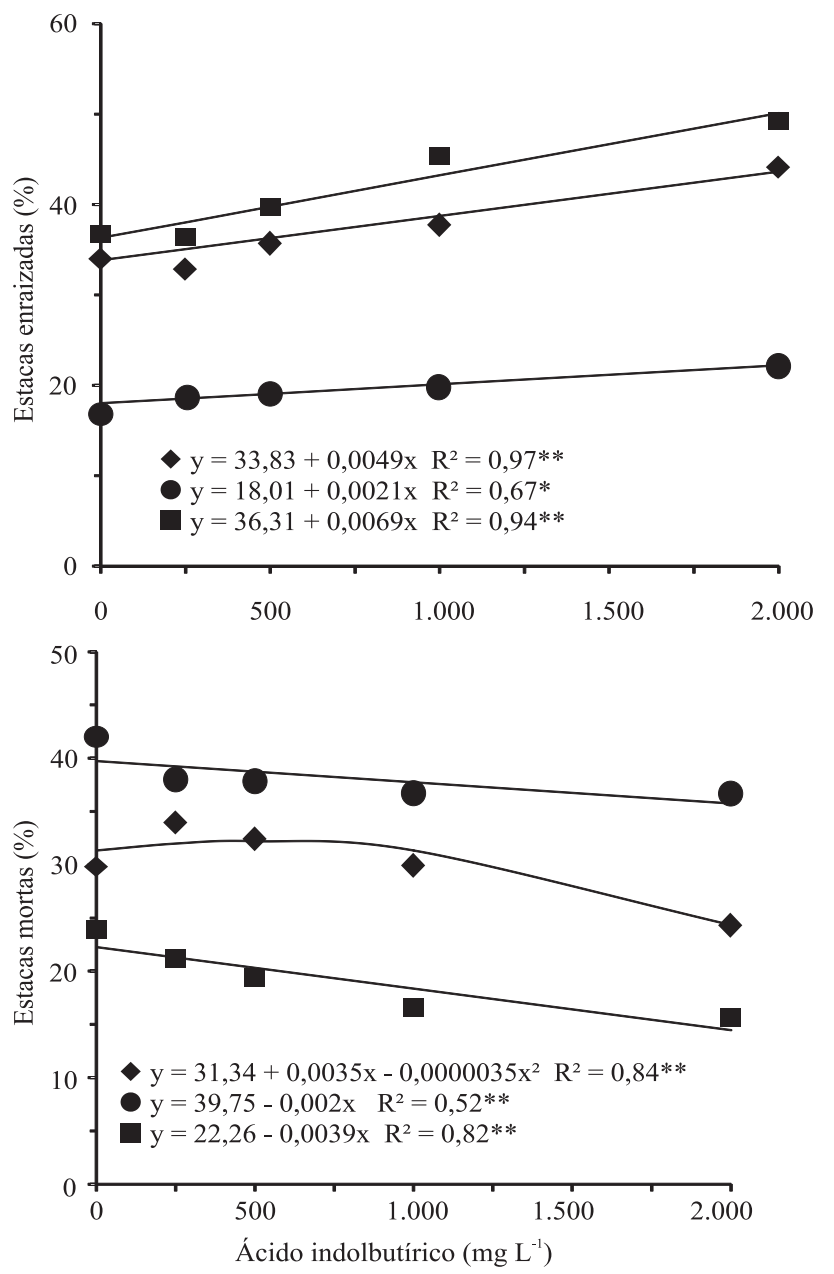

iniciadas pela divisão de células próximas ao câmbio vascular e ao floema (Hartmann et al., 2002). Como na primavera as plantas estavam em intensa atividade de crescimento, isso pode ter favorecido a maior formação de calos nas cultivares Bluebelle e Bluegem. Entretanto, a lesão na base das estacas não apresentou efeito significativo no enraizamento de estacas de mirtilo em outros trabalhos (Wagner Júnior et al., 2004; Trevisan et al., 2008).

Todas as cultivares avaliadas responderam à aplicação de AIB e apresentaram regressões lineares significativas (Figura 1). O aumento da concentração de AIB foi acompanhado do aumento da percentagem
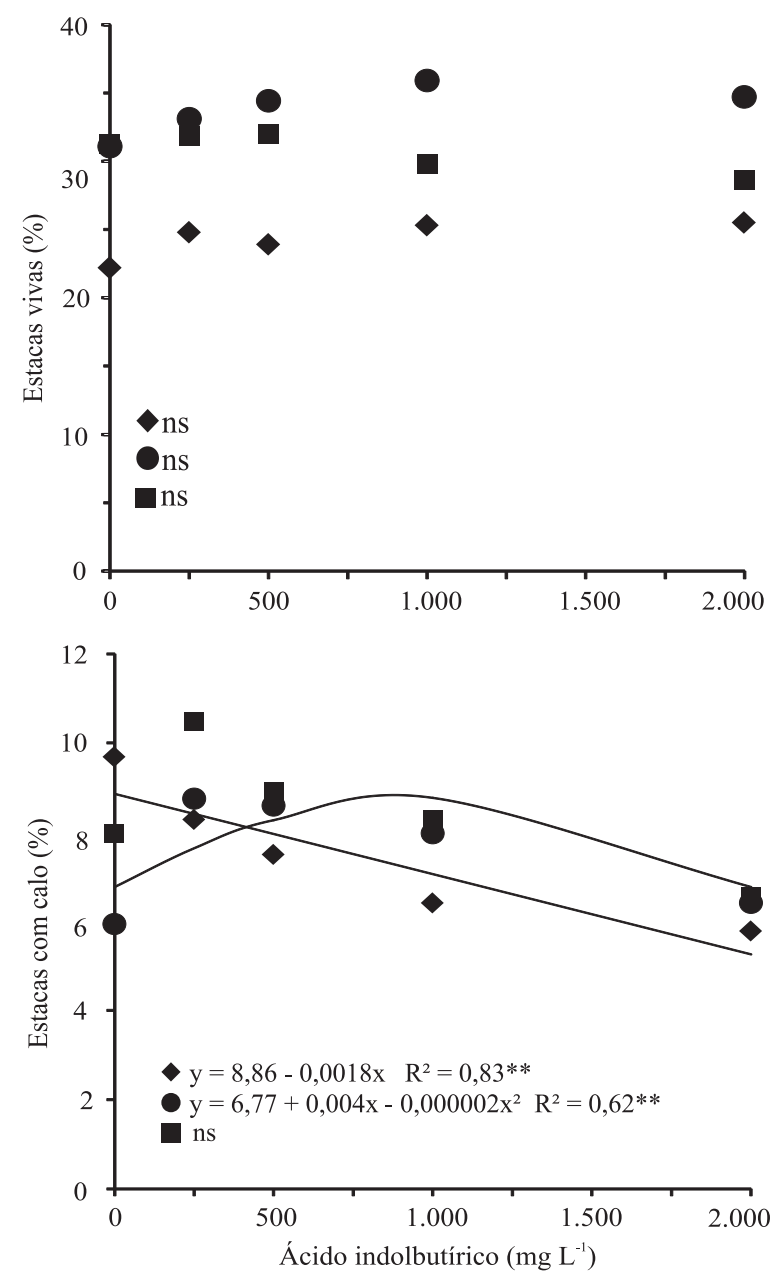

- Bluegem •Bluebelle $\quad$ Powderblue

Figura 1. Percentagem de estacas enraizadas, vivas, mortas e com calo das cultivares de mirtilo Bluegem, Bluebelle e Powderblue, em substrato com e sem aquecimento, nas quatro estações do ano, em diferentes concentrações de ácido indolbutírico. 
de enraizamento até a maior concentração testada, que foi de $2.000 \mathrm{mg} \mathrm{L}^{-1}$. Esta concentração também foi indicada para a microestaquia da porção apical de ramos da cultivar Climax (Schuch et al., 2007). O efeito positivo da aplicação de AIB também foi observado por Fischer et al. (2008b), na cultivar Powderblue, e a concentração de $1.000 \mathrm{mg} \mathrm{L}^{-1}$ foi a mais favorável. O efeito benéfico da aplicação de AIB no enraizamento de estacas de mirtilo também foi verificado para outras cultivares, como Florida e Climax, na estaquia realizada no final do verão (Peña et al., 2012), e Delite na estaquia de inverno (Fischer et al., 2008b). A obtenção de regressões lineares, no presente trabalho, é um indicativo de que maiores percentagens de enraizamento podem ser obtidas com maiores concentrações de AIB.

As cultivares Bluegem e Powderblue atingiram, em média, mais de $40 \%$ de enraizamento, enquanto a cultivar Bluebelle atingiu apenas 22\%. Fischer et al. (2008b) não obtiveram resposta desta cultivar à aplicação de AIB na estaquia lenhosa durante o inverno em Pelotas, RS. Contudo, na estaquia semilenhosa realizada durante o verão, esta cultivar apresentou resposta à aplicação de AIB, cuja melhor concentração foi a de $1.000 \mathrm{mg} \mathrm{L}^{-1}$ (Fischer et al., 2008a).

O aumento da concentração de AIB também causou redução da percentagem de estacas mortas, para as três cultivares testadas, e redução da percentagem de estacas apenas com calo nas cultivares Bluegem e Bluebelle. A percentagem de estacas vivas sem raízes não diferiu significativamente para todas as cultivares, tendo variado entre 23 e $35 \%$.

Para as variáveis número e comprimento médio de raízes emitidas por estaca, não houve interação significativa entre os fatores estações do ano, concentrações de AIB e aquecimento do substrato.

A estação do ano mais favorável à emissão e ao crescimento de raízes foi o verão, para todas as cultivares (Tabela 3 ). No verão, o número de raízes emitidas por estaca foi superior ao encontrado nas demais estações, em média 7,5 raízes na cultivar Powderblue, 5,6 na Bluegem e 3,3 na Bluebelle. O comprimento das raízes também foi superior, no verão, para as cultivares Powderblue e Bluegem, e, no verão e na primavera, na Bluebelle, que apresentou menor comprimento médio que as outras cultivares. $\mathrm{O}$ menor crescimento das raízes da cultivar Bluebelle também foi observado, em comparação à cultivar Delite (Fischer et al., 2008a).

A aplicação de AIB teve efeito significativo no número de raízes nas cultivares Bluebelle e Powderblue, que apresentaram regressões lineares significativas (Figura 2). $\mathrm{O}$ efeito positivo da aplicação de AIB no número de raízes foi observado em estacas lenhosas da cultivar Powderblue (Fischer et al., 2008b) e em estacas semilenhosas da cultivar Bluebelle (Fischer et al., 2008a). Para o comprimento das raízes, todas as cultivares responderam à aplicação de AIB, com regressões lineares significativas. A cultivar Bluebelle apresentou menor número e comprimento de raízes em comparação às outras cultivares, o que também foi verificado por Fischer et al. (2008a) com estacas semilenhosas, em que o uso de $1.000 \mathrm{mg} \mathrm{L}^{-1}$ de AIB promoveu maior número e comprimento de raízes.

$\mathrm{O}$ aquecimento do substrato praticamente não afetou o número e o comprimento das raízes. Constatou-se apenas efeito significativo para a cultivar Powderblue, em que o aquecimento aumentou o comprimento médio das raízes (Tabela 4).

Tabela 3. Número e comprimento de raízes emitidas por estaca das cultivares de mirtilo Bluegem, Bluebelle e Powderblue, tratadas com diferentes concentrações de ácido indolbutírico, em substrato com e sem aquecimento, sob efeito da estação do ano ${ }^{(1)}$.

\begin{tabular}{lcc}
\hline Estação & Número de raízes por estaca & Comprimento de raízes (cm) \\
\hline & \multicolumn{3}{c}{ 'Bluegem' } \\
Outono & $2,3 \mathrm{c}$ & $1,93 \mathrm{c}$ \\
Inverno & $2,9 \mathrm{bc}$ & $1,33 \mathrm{~d}$ \\
Primavera & $3,4 \mathrm{~b}$ & $3,52 \mathrm{~b}$ \\
Verão & $5,6 \mathrm{a}$ & $5,05 \mathrm{a}$ \\
\hline $\mathrm{CV}(\%)$ & 34,72 & 25,32 \\
\hline & & \\
Outono & $2,2 \mathrm{~b}$ & \\
Inverno & $2,1 \mathrm{~b}$ & $1,17 \mathrm{~b}$ \\
Primavera & $2,6 \mathrm{~b}$ & $0,66 \mathrm{c}$ \\
Verão & $3,3 \mathrm{a}$ & $2,58 \mathrm{a}$ \\
CV (\%) & 35,51 & $2,85 \mathrm{a}$ \\
\hline & & 31,88 \\
Outono & $4,1 \mathrm{~b}$ & \\
Inverno & $2,4 \mathrm{c}$ & $1,41 \mathrm{c}$ \\
Primavera & $3,5 \mathrm{~b}$ & $1,63 \mathrm{c}$ \\
Verão & $7,5 \mathrm{a}$ & $4,24 \mathrm{~b}$ \\
\hline CV (\%) & 40,24 & $6,97 \mathrm{a}$ \\
\hline
\end{tabular}

${ }^{(1)}$ Médias das diferentes concentrações seguidas de letras iguais não diferem, entre si, pelo teste de Tukey, a $5 \%$ de probabilidade. 

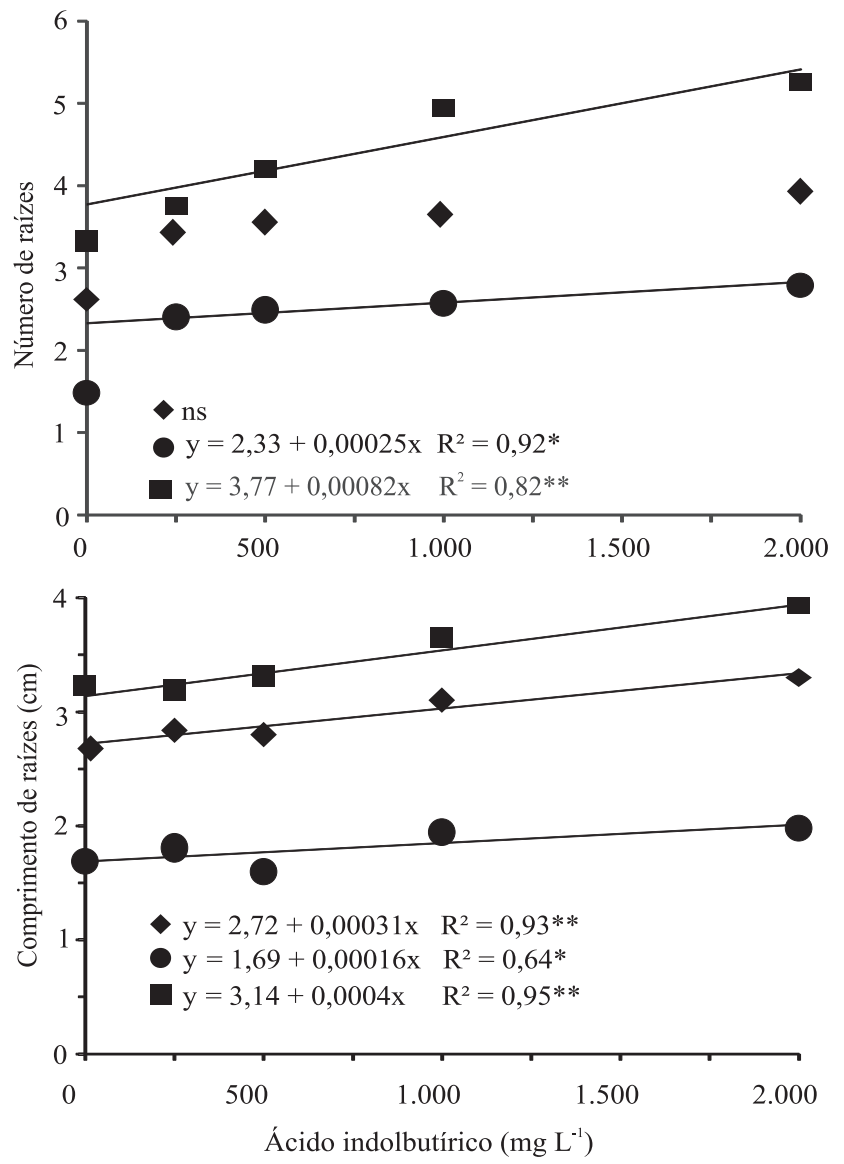

- Bluegem - Bluebelle $\square$ Powderblue

Figura 2. Número e comprimento de raízes emitidas por estaca das cultivares de mirtilo Bluegem, Bluebelle e Powderblue, em substrato com e sem aquecimento, nas quatro estações do ano, em diferentes concentrações de ácido indolbutírico.

Tabela 4. Número e comprimento de raízes emitidas por estaca das cultivares de mirtilo Bluegem, Bluebelle e Powderblue, tratadas com diferentes concentrações de ácido indolbutírico, nas quatro estações do ano, sob efeito do aquecimento do substrato ${ }^{(1)}$.

\begin{tabular}{|c|c|c|}
\hline Aquecimento & Número de raízes por estaca & Comprimento de raízes $(\mathrm{cm})$ \\
\hline & \multicolumn{2}{|c|}{ 'Bluegem' } \\
\hline Sem & $3,4^{\mathrm{ns}}$ & $2,8 \mathrm{a}$ \\
\hline Com & 3,7 & $3,1 \mathrm{a}$ \\
\hline \multirow[t]{2}{*}{$\mathrm{CV}(\%)$} & 34,72 & 25,32 \\
\hline & \multicolumn{2}{|c|}{ 'Bluebelle' } \\
\hline Sem & $2,41^{\text {ns }}$ & $1,7^{\mathrm{ns}}$ \\
\hline Com & 2,63 & 1,8 \\
\hline \multirow[t]{2}{*}{$\mathrm{CV}(\%)$} & 35,51 & 31,88 \\
\hline & \multicolumn{2}{|c|}{ 'Powderblue' } \\
\hline Sem & $4,1 \mathrm{a}$ & $3,3 \mathrm{~b}$ \\
\hline Com & $4,6 \mathrm{a}$ & $3,6 \mathrm{a}$ \\
\hline $\mathrm{CV}(\%)$ & 40,24 & 22,84 \\
\hline
\end{tabular}

\section{Conclusões}

1. As cultivares Bluegem e Powderblue sofrem influência da época de coleta de estacas, e o verão é a melhor estação de coleta.

2. O ácido indolbutírico, na concentração de $2.000 \mathrm{mg} \mathrm{L}^{-1}$, aumenta o enraizamento de estacas das cultivares Bluegem e Powderblue.

3. $\mathrm{O}$ aquecimento do substrato melhora o enraizamento das estacas coletadas no outono e no inverno, nas cultivares Bluegem, Bluebelle e Powderblue, e, também, das estacas coletadas no verão e na primavera, na cultivar Bluebelle.

\section{Referências}

ANTUNES, L.E.C. Introdução. In: RASEIRA, M. do C.B.; ANTUNES, L.E.C. (Ed.). Cultivo do mirtilo (Vaccinium spp). Pelotas: Embrapa Clima Temperado, 2006. p.13-16. (Embrapa Clima Temperado. Sistemas de produção, 8).

ANTUNES, L.E.C.; GONÇALVES, E.D.; RISTOW, N.C.; CARPENEDO, S.; TREVISAN, R. Fenologia, produção e qualidade de frutos de mirtilo. Pesquisa Agropecuária Brasileira, v.43, p.1011-1015, 2008. DOI: 10.1590/S0100-204X2008000800009.

BANADOS, M.P. Blueberry production in South America. Acta Horticulturae, v.715, p.165-172, 2006.

BECCARO, G.; MELLANO, M.G.; BOTTA, R.; CHIABRANDO, V.; BOUNOUS, G. Phenolic and anthocyanin content and antioxidant activity in fruits of bilberry (Vaccinium myrtillus L.) and of highbush blueberry ( $V$. corymbosum L.) cultivars in North Western Italy. Acta Horticulturae, v.715, p.553-557, 2006.

BORDIN, I.; HIDALGO, P.C.; BÜRKLE, R.; ROBERTO, S.R. Efeito da presença da folha no enraizamento de estacas semilenhosas de porta-enxertos de videira. Ciência Rural, v.35, p.215-218, 2005. DOI: 10.1590/S0103-84782005000100035.

DAMIANI, C.R.; SCHUCH, M.W. Enraizamento in vitro de mirtilo em condições fotoautotróficas. Ciência Rural, v.39, p.1012-1017, 2009. DOI: 10.1590/S0103-84782009005000031.

FACHINELLO, J.C.; HOFFMANN, A.; NACHTIGAL, J.C.; KERSTEN, E. Propagação vegetativa por estaquia. In: FACHINELLO, J.C.; HOFFMANN, A.; NACHTIGAL, J.C. (Ed.). Propagação de plantas frutíferas. Brasília: Embrapa Informação Tecnológica, 2005. p.69-109.

FOOD AND AGRICULTURE ORGANIZATION OF THE UNITED NATIONS. Food and agricultural commodities production. Roma: FAO, 2012. Available at: <http://faostat.fao. org/site/339/default.aspx>. Access on: 18 jun. 2012.

FISCHER, D.L. de O.; FACHINELLO, J.C.; ANTUNES, L.E.C.; TIMM, C.R.F.; GIACOBBO, C.L. Enraizamento de estacas semilenhosas de mirtilo sob o efeito de diferentes concentrações de ácido indolbutírico. Revista Brasileira de Fruticultura, v.30, p.557-559, 2008a. DOI: 10.1590/S0100-29452008000200051. 
FISCHER, D.L. de O.; FACHINELLO, J.C.; ANTUNES, L.E.C.; TOMAZ, Z.F.P.; GIACOBBO, C.L. Efeito do ácido indolbutírico e da cultivar no enraizamento de estacas lenhosas de mirtilo. Revista Brasileira de Fruticultura, v.30, p.285-289, 2008b. DOI: 10.1590/S0100-29452008000200003.

FOCHESATO, M.L.; MARTINS, F.T.; SOUZA, P.V.D.; SCHWARZ, S.F.; BARROS, I.B.I. Propagação de louro (Laurus nobilis L.) por estacas semilenhosas com diferentes quantidades de folhas e tratadas com ácido indolbutírico. Revista Brasileira de Plantas Medicinais, v.8, p.72-77, 2006.

HARTMANN, H.T; KESTER, D.E.; DAVIES JUNIOR, F.T.; GENIVE, R.L. Plant propagation: principles and practices. 7.ed. New Jersey: Prentice Hall, 2002. 880p.

HOFFMANN, A.; FACHINELlO, J.C.; SANTOS, A.M. dos. Propagação de mirtilo (Vaccinium ashei Reade) através de estacas. Pesquisa Agropecuária Brasileira, v.30, p.231-236, 1995.

LIMA, D.M. de; ALCANTARA, G.B. de; FOGAÇA, L.A.; QUOIRIN, M.; CUQUEL, F.L.; BIASI, L.A. Influência de estípulas foliáceas e do número de folhas no enraizamento de estacas semilenhosas de maracujazeiro amarelo nativo. Acta Scientiarum. Agronomy, v.29, p.671-676, 2007. DOI: 10.4025/ actasciagron.v29i5.744.

MADAIL, J.C.M.; SANTOS, A.M. dos. Aspectos econômicos do mirtilo. In: RASEIRA, M. do C.B.; ANTUNES, L.E.C. (Ed.). Cultivo do mirtilo (Vaccinium spp). Pelotas: Embrapa Clima Temperado, 2006. p.93-96. (Embrapa Clima Temperado. Sistemas de produção, 8).

MARTINUSSEN, I.; NILSEN, H.; ROTHE, G.; LUND, L.; KAPP, K. Seasonal variations in rooting of lingonberry (Vaccinium Vitis-idaea L.) cuttings. Acta Horticulturae, v.715, p.439-442, 2006.

PASSARDI, F.; COSIO, C.; PENEL, C.; DUNAND, C. Peroxidases have more functions than a Swiss army knife. Plant Cell Reports, v.24, p.255-265, 2005. DOI: 10.1007/s00299-005-0972-6.

PELIZZA, T.R.; DAMIANI, C.R.; RUFATO, A. de R.; SOUZA, A.L.K. de; RIBEIRO, M. de F.; SCHUCH, M.W. Microestaquia em mirtileiro com diferentes porções do ramo e substratos. Bragantia, v.70, p.319-324, 2011. DOI: 10.1590/S0006-87052011000200010.

PEÑA, M.L.P.; GUBERT, C.; TAGLIANI, M.C.; BUENO, P.M.C.; BIASI, L.A. Concentrações e formas de aplicação do ácido indolbutírico na propagação por estaquia dos mirtileiros cvs. Flórida e Clímax. Semina: Ciências Agrárias, v.33, p.57-64, 2012. DOI: $10.5433 / 1679-0359.2012 v 33 n 1 p 57$.

PILlER, G.; FUKUSHIMA, M.; BROOM, F.; IWAHORI, S. A carbon based model of adventitious root formation: examples from blueberry propagation. Acta Horticulturae, v.574, p.393-399, 2002.

RODRIGUES, E.; POERNER, N.; ROCKENBACH, I.I.; GONZAGA, L.V.; MENDES, C.R.; FETT, R. Phenolic compounds and antioxidant activity of blueberry cultivars grown in Brazil. Ciência e Tecnologia de Alimentos, v.31, p.911-917, 2011.

SCHUCH, M.W.; DAMIANI, C.R.; SILVA, L.C. da; ERIG, A.L. Micropropagação como técnica de rejuvenescimento em mirtilo (Vaccinium ashei Reade) cultivar climax. Ciência e Agrotecnologia, v.32, p.814-820, 2008. DOI: 10.1590/S141370542008000300017.

SCHUCH, M.W.; DE ROSSI, A.; DAMIANI, C.R.; SOARES, G.C. Aib e substrato na produção de mudas de mirtilo cv. "Climax" através de microestaquia. Ciência Rural, v.37, p.1446-1449, 2007. DOI: $10.1590 / \mathrm{S} 0103-84782007000500036$.

TREVISAN, R.; FRANZON, R.C.; FRITSCHE NETO, R.; GONÇALVES, R. da S.; GONÇALVES, E.D.; ANTUNES, L.E.C. Enraizamento de estacas herbáceas de mirtilo: influência da lesão na base e do ácido indolbutírico. Ciência e Agrotecnologia, v.32, p.402-406, 2008. DOI: 10.1590/S1413-70542008000200009

WAGNER JÚNIOR, A.; COUTO, M.; RASEIRA, M. do C.B.; FRANZON, R.C. Efeito da lesão basal e do ácido indolbutírico no enraizamento de estacas herbáceas de quatro cultivares de mirtilo. Revista Brasileira de Agrociência, v.10, p.251-253, 2004.

ZHANG, Z.; LIU, H.; WU, L.; WU, L.; LI, Y. Technical system of blueberry micropropagation in China. Acta Horticulturae, v.715, p.421-425, 2006.

Recebido em 22 de junho de 2012 e aprovado em 9 de janeiro de 2013

Pesq. agropec. bras., Brasília, v.48, n.1, p.25-32, jan. 2013

DOI: 10.1590/S0100-204X2013000100004 